\title{
Spinal anesthetic management for discectomy in a patient with amyotrophic lateral sclerosis -A case report-
}

\author{
Ki-Bum Park ${ }^{1}$, Byungdoo Son ${ }^{1}$, Doo-Youn Hwang ${ }^{1}$, and Younghoon Jeon ${ }^{2}$ \\ Department of Anesthesiology and Pain Medicine, ${ }^{1}$ College of Medicine, Kyungpook National University, ${ }^{2}$ School of Dentistry, \\ Kyungpook National University, Daegu, Korea
}

Amyotrophic lateral sclerosis (ALS), also referred to as Lou Gehrig's disease, is a degenerative disorder of motor neuron system of the spinal cord and the cortical neuron. Patients with ALS present a unique challenge to the anesthesiologist. Respiratory muscle weakness, for instance, can result in trouble with proper breathing after general anesthesia. We report a case of spinal anesthesia for discectomy in a patient with ALS. (Korean J Anesthesiol 2012; 63: 547-549)

Key Words: Amyotrophic lateral sclerosis, Discectomy, Spinal anesthesia.

Amyotrophic lateral sclerosis (ALS) is a progressive neurodegenerative disease that affects the upper and the lower motor neurons. The clinical features can be considered in relation to neurological regions or levels. Physical signs of this disorder encompass both, the upper and the lower motor neuron findings. Atrophy and weakness of respiratory muscles eventually lead to respiratory failure and death. General anesthesia may cause fatal respiratory depression because the response to muscle relaxants is sensitive in ALS patients. Lumbar epidural anesthesia was done safely for low abdominal surgery in a patient with ALS [1]. But neuroaxial anesthesia may exacerbate pre-existing neurologic disease [2]. We report a case of spinal anesthesia for discectomy in a patient with ALS.

\section{Case Report}

A 64-year-old man, $165 \mathrm{~cm}$ in height and $70 \mathrm{~kg}$ in weight, visited the department of neurosurgery due to severe pain on the left lateral leg. On physical examination, left ankle dorsiflextion was impaired. Magnetic resonance imaging (MRI) of lumbosacral vertebral column showed a left paramedian disc extrusion, between lumbar 4 and 5 vertebras. The patient was scheduled for discectomy. In premedical history, the patient complained of dysarthria, dysphagia and weakness in both legs, while walking 3 years ago. He also complained of dyspnea, although, there were no abnormalities on the blood gas analysis. On the physical findings by a neurologist, deep tendon

Received: November 29, 2011. Revised: 1st, January 16, 2012; 2nd, February 9, 2012; 3rd, February 27, 2012. Accepted: February 27, 2012. Corresponding author: Younghoon Jeon, M.D., Ph.D., Department of Anesthesiology and Pain Medicine, School of Dentistry, Kyungpook National University, 188-1, Samdeok-dong 2-ga, Jung-gu, Daegu 700-412, Korea. Tel: 82-53-420-5871, Fax: 82-53-426-2760, E-mail: jeon68@knu.ac.kr C) This is an open-access article distributed under the terms of the Creative Commons Attribution Non-Commercial License (http:// creativecommons.org/licenses/by-nc/3.0/), which permits unrestricted non-commercial use, distribution, and reproduction in any medium, provided the original work is properly cited. 
reflex was exacerbated and babinski test was positive. The electromyogram (EMG) suggested that the patient had a motor neuron disease and he was diagnosed with ALS. Pulmoary function test was not performed before the operation, due to the undergoing emergency operation for resolution of severe pain on the left leg.

Spinal anesthesia for discectomy was chosen to avoid respiratory complication, which is associated with general anesthesia. No preanesthetic medication was given. Spinal anesthesia was done between lumbar 3 and 4, via a midline approach in the left lateral position and was injected with 10 mg of $0.5 \%$ hyperbaric bupivacaine, plus fentanyl $20 \mu \mathrm{g}$ using a 25 guage Quinke spinal needle. Immediately after the injection of local anesthetic agent and opioid, the patient was placed back to the supine position. The level of the spinal anesthesia was T10, after 15 minutes and then we changed the patient's position from supine to prone position. Propofol at a rate of $0.5-1.0 \mathrm{mg} / \mathrm{kg} / \mathrm{hr}$ was infused for sedation with $\mathrm{O}_{2} 5 \mathrm{~L} / \mathrm{min}$ via nasal cannula. Intraoperatively, vital signs were as follows: blood pressure of 122 to $139 / 81$ to $95 \mathrm{mmHg}$; heart rate between 75 and 97 beats/min; and oxygen saturation of $100 \%$. There were no complications for one and a half hour of the surgery. The patient was monitored for one hour, in postoperative anesthetic care units (PACU), and then was discharged from PACU. The patient was fully recovered at 5 hours, after the spinal anesthesia and no exacerbation of neurologic signs or symptoms were revealed. The patient was discharged two days after surgery and at the 3 months follow-up, there were no neurologic complications due to spinal anesthesia.

\section{Discussion}

ALS is a fatal neurodegenerative disease. Patients with ALS become progressively paralyzed, while remaining fully alert mentally, due to degeneration of the upper and the lower motor neurons in the brain and spinal cord. Brain stem involvement produces dysarthria (slurred speech), dysphagia, and aspiration [3]. Respiratory insufficiency is one of the most critical issues for the majority of patients with ALS, and thus, there has been a great concern regarding the effects of anesthetic management on respiratory function. General anesthesia may cause aspiration and/or ventilatory depression, due to abnormal responses to muscle relaxants [4]. In general anesthesia, dose of nondepolarizing muscle relaxant should be reduced [5] or avoided [6] because of the possible occurrence of ventilatory depression because of abnormal responses to muscle relaxants. Therefore, regional anesthesia can be considered a safer modality than that of general anesthesia, on the respiration system, in low extremity or abdominal operation. Recently, there was the case that combines epidural and spinal anesthesia was undergone for the operation of femur fracture of a patient with ALS, without complication [7]. But it was reported that neuroaxial anesthesia could exacerbate pre-existing neurologic disease [8]. Because of demyelination, which is associated with motor neuron diseases, the spinal cord is more susceptible to the potential neurotoxic effects of local anesthetics [2]. However, Hebl et al. [9] investigated the frequency of new or progressive neurologic complications in 139 patients with a confirmed, preexisting CNS disorder that underwent neuroaxial anesthesia or analgesia. They suggested that the risks that are commonly associated with neuroaxial anesthesia and analgesia in patients, with preexisting central nerve system (CNS) disorders, may not be as frequent as once thought (95\% confidence interval, $0.0-$ $0.3 \%$ ). Further, neuroaxial blockade should not be considered absolute contraindication within this population of patients.

Silver et al. [10] reported 576 cases of operations on the herniated lumbar disc under the spinal anesthesia. They concluded that proper administration of spinal anesthesia for the herniated lumbar disc is a safe procedure.

Patients with ALS have characteristic abnormalities in pulmonary function, including reduced vital capacity (VC) [11]. Level of block in regional anesthesia affects respiratory function. For example, in epidural anesthesia, sensory block above T6 reduces the expiratory reserve volume (ERV) and it may depress respiration [12]. High level of block can result in the inability to cough effectively, which leads to a reduced clearance of secretions from the airway. Hara et al. [13] reported that epidural anesthesia temporally decreased VC, in the immediate postoperative period, without any neurologic exacerbation.

Body position also exerts a strong effect on the pulmonary function. Knee chest position and prone position are mostly used for lumbar discectomy. Yilmaz et al. [14] found that forced expiratory volume in 1 second (FEV1), peak expiratory Flow (PEF) and forced expiratory flow 25 (FEF25), significantly decreased in the knee-chest group, compared with that of the prone group. The knee-chest position could cause a restrictive effect. Propofol does not have any effects on neuromuscular junction. In addition, propofol has a high clearance rate, which contributes to a relatively rapid recovery after continuous infusion [15]. Therefore, we selected propofol for the sedation of this patient.

In conclusion, in this case, no neurologic deteriorations were observed, after spinal anesthesia for discectomy in a patient with ALS. Therefore, we suggested that spinal anesthesia can be an alternative option for discectomy in a patient with ALS.

\section{References}

1. Kochi T, Oka T, Mizuguchi T. Epidural anesthesia for patients with amyotrophic lateral sclerosis. Anesth Analg 1989; 68: 410-2. 
2. Warren TM, Datta S, Ostheimer GW. Lumbar epidural anesthesia in a patient with multiple sclerosis. Anesth Analg 1982; 61: 1022-3.

3. Ferguson TA, Elman LB. Clinical presentation and diagnosis of amyotrophic lateral sclerosis. NeuroRehabilitation 2007; 22: 409-16.

4. Pasternak JJ, Lanier WL Jr. Anesthesia and Co-Existing Disease. 5th ed. Philadelphia, Churchill Livingstone. 2008, pp 245-6.

5. Rosenbaum KJ, Neigh JL, Strobel GE. Sensitivity to nondepolarizing muscle relaxants in amyotrophic lateral sclerosis: report of two cases. Anesthesiology 1971; 35: 638-41.

6. Lee D, Lee KC, Kim JY, Park YS, Chang YJ. Total intravenous anesthesia without muscle relaxant in a patient with amyotrophic lateral sclerosis. J Anesth 2008; 22: 443-5.

7. Hobaika AB, Neves BS. Combined spinal-epidural block in a patient with amyotrophic lateral sclerosis: case report. Rev Bras Anestesiol 2009; 59: 206-9.

8. Dripps RD, Vandam LD. Exacerbation of pre-existing neurologic disease after spinal anesthesia. N Engl J Med 1956; 255: 843-9.

9. Hebl JR, Horlocker TT, Schroeder DR. Neuraxial anesthesia and analgesia in patients with preexisting central nervous system disorders. Anesth Analg 2006; 103: 223-8.

10. Silver DJ, Dunsmore RH, Dickson CM. Spinal anesthesia for lumbar disc surgery: Review of 576 operations. Anesth Analg 1976; 55: 5504.

11. Fallat RJ, Jewitt B, Bass M, Kamm B, Norris FH Jr. Spirometry in amyotrophic lateral sclerosis. Arch Neurol 1979; 36: 74-80.

12. Stoeling RK, Dierdorf SF. Anesthesia and Co-Existing Disease. 4th ed. New York, Churchill Livingstone. 2002, pp 186.

13. Hara K, Sakura S, Saito Y, Maeda M, Kosaka Y. Epidural anesthesia and pulmonary function in a patient with amyotrophic lateral sclerosis. Anesth Analg 1996; 83: 878-9.

14. Yilmaz C, Buyrukcu SO, Cansever T, Gulsen S, Altinors N, Caner H. Lumbar microdiscectomy with spinal anesthesia: comparison of prone and knee-chest positions in means of hemodynamic and respiratory function. Spine (Phila Pa 1976) 2010; 35: 1176-84.

15. Morgan GE, Mikhail MS, Murray MJ. Clinical Anesthesiology. 4th ed. New York, McGraw-hill. 2005, pp 200-1. 